\title{
Cone-beam computed tomography analysis on root and canal morphology of mandibular first permanent molar among multiracial population in East Coast Malaysian population
}

\author{
Prunella Ubung Deng ${ }^{1}$, Mohamad Syahrizal Halim ${ }^{1,5}$, Sam'an Malik Masudi ${ }^{2}$, \\ Saaid Al-Shehadat ${ }^{3}$, Basaruddin Ahmad ${ }^{4}$
}

Correspondence: Dr. Mohamad Syahrizal Halim

Email: drsyah@usm.my

\begin{abstract}
'Department of Conservative Dentistry, School of Dental Sciences,Universiti Sains Malaysia, Health Campus, Kubang Kerian, Kelantan, Malaysia, 2Department of Conservative Dentistry, Faculty of Dentistry, Lincoln University College, Selangor, Malaysia,

${ }^{3}$ Department of Preventive and Restorative Dentistry, College of Dental Medicine, Sharjah University, Sharjah, UAE,

${ }^{4}$ Department of Dental Public Health, School of Dental Sciences, Universiti Sains Malaysia, Health Campus, Kubang Kerian, Kelantan, Malaysia,

${ }^{5}$ Hospital USM, Health Campus, USM, Kubang Kerian, Kelantan, Malaysia
\end{abstract}

\section{ABSTRACT}

Objective: The aim of this study is to investigate the variations in the number of root and canal in the mandibular first permanent molars (MFPMs) teeth in East Coast Malaysian population using cone-beam computed tomography (CBCT). Materials and Methods: CBCT images which show MFPMs recorded in HUSM Dental Clinic between January 2015 and June 2016 was obtained and analyzed for their number of roots and canals. A total of 208 CBCT images of MFPMs were collected; 118 patients had unilateral molars and 90 patients had bilateral molars. The following observations were made: (1) root number; (2) number of canals per root; and (3) comparisons of number of roots and canals according to gender, ethnicity, and position. Results: The majority of cases of bilateral MFPM had the same number of roots $(95.6 \%, 95 \%$ confidence interval [CI]: $89.01 \%, 98.78 \%)$ on both the right and left side and only 4 cases $(4.4 \%, 95 \% \mathrm{CI}: 1.22 \%, 10.99 \%)$ had 3 roots on the right and 2 roots on the left sides. The majority of cases had the same number of canals on both sides $(66.7 \%, 95 \% \mathrm{CI}$ : 55.95, 76.26\%) and $33.3 \%$ (95\% CI: 23.74\%, 44.05\%) with unequal number of canals. The occurrence of the number of canals was not independent of the sides of the $\operatorname{arch}(P<0.001)$ and there was statistically significantly greater proportion of cases who had greater number of canals on the right side than the left $(P=0.03)$. The prevalence of right single-rooted MFPM was very small at $0.3 \%(n=1)$ in a Malay male $(95 \% \mathrm{CI}: 0.00,1.83)$ and the most prevalent was two roots first molar $(88.4 \%)$. The number of roots was not associated with sex or ethnic group $(P>0.05)$. The MFPM with a single root was found to have only one mesial canal. For two rooted MFPM, the most prevalent occurrence was

This is an open access journal, and articles are distributed under the terms of the Creative Commons Attribution-NonCommercial-ShareAlike 4.0 License, which allows others to remix, tweak, and build upon the work non-commercially, as long as appropriate credit is given and the new creations are licensed under the identical terms.

\begin{tabular}{|l|l|}
\hline \multicolumn{2}{|c|}{ Access this article online } \\
\hline Quick Response Code: \\
\hline
\end{tabular}

For reprints contact: reprints@medknow.com

How to cite this article: Deng PU, Halim MS, Masudi SM,
Al-Shehadat S, Ahmad B. Cone-beam computed tomography analysis
on root and canal morphology of mandibular first permanent molar
among multiracial population in East Coast Malaysian population. Eur
J Dent 2018;12:410-6.
DOI: $10.4103 /$ ejd.ejd_82_18 
two canals at the mesial and one canal at the distal roots (59\%); followed by single canals in each mesial and distal (21\%) and double canals per root (18\%). Three roots MFPM have either single or double canals in the mesial root and double canals in the distal root. Conclusions: The majority of population in the East Coast region of Malaysia has two roots and three root canals in their MFPMs. There was no difference in the number of roots between gender and ethnic and canals between ethnic.

Key words: Cone-beam computed tomography, Malaysian population, mandibular first permanent molar anatomy, root canal anatomy

\section{INTRODUCTION}

The success of endodontic therapy is very much related to the procedure performed during the treatment which includes locating and identifying the root canals, removing the pulp tissue, cleaning and shaping, obturating the canal(s), and placing a permanent restoration. However, all root canal needs to be identified and located before the procedure is performed and misidentification of roots and canal number may lead to endodontic failure. ${ }^{[1,2]}$ Enumerating the root canals may pose a challenge due to the variation in the anatomy of root canal system which varies between teeth, individuals, and ethnics. ${ }^{[3-12]}$

Mandibular first permanent molar (MFPM) is among the common first permanent tooth to erupt and also to be extracted. ${ }^{[13]}$ This is due to prolonged duration of insult, resulting from the continuous process of demineralization-remineralization in the oral cavity, and once the balance tipped toward demineralization, caries lesion starts to appear. This makes the MFPM among the first teeth to develop caries among the permanent dentition and progress deeper toward root canal system without any monitoring and treatment. A carious lesion that involved the pulp or root canal system is usually large and resulted in the need for either extraction or root canal treatment. It also has been found that the major reason for tooth loss of this MFPM is caries, followed by endodontic failure. ${ }^{[2]}$

Several studies have examined the root and canal morphology of mandibular first molars in different races and gender. ${ }^{[3,14-17]}$ The variation in morphology of each root canal was so unique that it is suggested to be genetically and racially inflicted. ${ }^{[3,18]}$ However, these studies used conventional two-dimensional (2D) periapical radiograph and demineralization-staining technique.

Advanced technology has allowed for the applications of cone-beam computed tomography (CBCT) as a tool in dental diagnostic. ${ }^{[6,7,14,16]}$ It provides $3 \mathrm{D}$ information and has been shown to be a good method for pretreatment assessment of root and canal morphology. ${ }^{[19]}$ CBCT modalities were able to overcome the superimposition of surrounding structures and the $3 \mathrm{D}$ reconstruction makes it superior than conventional periapical radiograph. ${ }^{[1]}$ The ability of this new radiographic modality allows research to be done without tissue destruction and functioning natural tooth in the oral cavity.

The MFPM typically has two roots, one each at the mesial and distal and; three canals, two in the mesial root and one in distal root. ${ }^{[3,6,7,13-17]}$ However, these were from Sudanese, Turkish, Korean, Indian, Senegal, Chinese, and Kuwaiti populations, and at present, there is scarce data on root and canal morphology of mandibular first molars from Malaysian population, Hence, the aim of this study was to describe the number of roots and canals of MFPM and the variations between the different ethnics in East Coast Malaysian population.

\section{MATERIALS AND METHODS}

Samples were patients whom had attended the Hospital Universiti Sains Malaysia (USM) Dental Clinic. They have CBCT images taken as part of investigation before treatment and archived in the Radiology Unit, School of Dental Sciences, USM. The CBCT images were taken by one licensed radiologist using 3D Planmeca Promax (Finland) with scan setting at $90 \mathrm{kVp}, 10 \mathrm{~mA}$, field of view $80 \mathrm{~mm} \times 80 \mathrm{~mm}$, voxel size $320 \mu \mathrm{m}$, and dosage of $1233 \mathrm{DAP}\left(\mathrm{mGyX}_{\mathrm{cm}}\right)$. The approval for the use of the images was obtained from the Human Research Ethics Committee, USM (JEPeM Code: USM/JEPeM/16030122). A case was included if the patient's age was between 10 and 70 years old, information on sex and ethnicity, and good-quality CBCT images that includes the right MFPM with fully formed apex, and without periapical lesion, root canals filling, and crown restoration was available. For selected number of cases, both the right and left side of MFPM were recorded.

The 3D image was analyzed using Romexis 2.9.2 $\mathrm{R}$ software (Planmeca promax Planmeca Oy Asentajankatu 6 FIN-00880 Helsinki, Finland) in a 
specific room for radiographic analysis. The images were displayed on 20-inch LCD Monitor at resolution $1280 \times 1024$ pixels. The image magnification and contrast were adjusted until optimal visualization was achieved. The analysis was performed by moving the images to browse the entire root canal anatomy from the canal orifices to the root apex. Observation on the number of roots and root canals, number of canals per root were recorded. Other demographic information includes the gender and ethnic group.

\section{Statistical analysis}

Descriptive analysis was used to describe the sample and the prevalence of canals and roots of MFPM.

Chi-squared test was used toexamine theindependence of the number of roots in cases with bilateral MFPM and the sides of the arch. McNemar-Bowker test was used to compare the contralateral proportion of the number of roots. Analysis was carried out using SPSS v22, (SPSS, v22, IBM Statistic, California, USA), and significant level was set at $5 \%$.

\section{RESULTS}

A total of 301 cases including 90 cases with bilateral MFPM were examined [Table 1]. There were more female cases (56\%) and the majority were from Malay ethnic group (79\%). The distribution of cases with bilateral MFPM is as in Table 2. The majority of cases of bilateral MFPM had the same number of roots (95.6\%, 95\% confidence interval [CI]: 89.01\%, 98.78\%) on both right and left side and only 4 cases $(4.4 \%, 95 \%$ CI: $1.22 \%, 10.99 \%$ ) had 3 roots on the right and 2 roots on the left sides. Analysis showed that the occurrence of number of roots was not associated with the side of the arch $(P=0.3)$. The majority of cases had the same number of canals on both sides $(66.7 \%, 95 \%$ CI: $55.95,76.26 \%)$ and $33.3 \%$ (95\% CI: $23.74 \%, 44.05 \%)$ with unequal number of canals. However, the occurrence of the number of canals was not independent of the sides of the arch $(P<0.001)$ and there was the statistically significantly greater proportion of cases who had greater number of canals on the right side than the left $(P=0.03)$.

Examination of the right MFPM only showed that the prevalence of single-rooted first permanent molar was very small at $0.3 \%(n=1)$ in a Malay male (95\% CI: $0.00,1.83$ ) and the most prevalent was two roots first molar (88.4\%) [Table 3]. The number of roots was not associated with sex or ethnic group $(P>0.05)$. There was also one case of single canal MFPM and

\begin{tabular}{|c|c|c|}
\hline & MFPM $(n=301)$ & Bilateral MFPM $(n=90)$ \\
\hline \multicolumn{3}{|l|}{ Sex } \\
\hline Male & 132 (43.9) & $43(47.8)$ \\
\hline Female & $169(56.1)$ & $47(52.2)$ \\
\hline \multicolumn{3}{|l|}{ Ethnic } \\
\hline Malay & $236(78.4)$ & $69(76.7)$ \\
\hline Chinese & $54(17.9)$ & $17(18.9)$ \\
\hline Indian & $11(3.7)$ & $4(4.4)$ \\
\hline
\end{tabular}

\begin{tabular}{|c|c|c|c|c|}
\hline \multirow{2}{*}{ Tooth 46} & \multicolumn{3}{|c|}{ Tooth 36} & \multirow{2}{*}{$\begin{array}{c}\text { Total } \\
(n=90)\end{array}$} \\
\hline & Two & Three & Four & \\
\hline \multicolumn{5}{|c|}{ Number of roots } \\
\hline Two & $79(87.8)$ & 0 & - & 79 (87.8) \\
\hline Three & $4(4.4)$ & $7(7.8)$ & - & $11(12.2)$ \\
\hline \multicolumn{5}{|c|}{ Number of canals } \\
\hline Two & $13(14.4)$ & $7(7.8)$ & $1(1.1)$ & $21(23.3)$ \\
\hline Three & $8(8.9)$ & $39(43.3)$ & $1(1.1)$ & $48(53.3)$ \\
\hline Four & $1(1.1)$ & $11(12.2)$ & $8(8.9)$ & $20(22.2)$ \\
\hline Five & 0 & $1(1.1)$ & 1 & $1(1.1)$ \\
\hline
\end{tabular}

\begin{tabular}{|c|c|c|c|c|c|}
\hline & One & Two & Three & Total & $P^{*}$ \\
\hline \multicolumn{6}{|l|}{ Sex } \\
\hline Male & $1(0.8)$ & 117 (88.6) & $14(10.6)$ & 132 & 0.6 \\
\hline Female & 0 & 149 (88.2) & $20(11.8)$ & 169 & \\
\hline \multicolumn{6}{|l|}{ Ethnic } \\
\hline Malay & $1(0.4)$ & 208 (88.1) & $27(11.4)$ & 237 & 0.7 \\
\hline Chinese & 0 & $47(87.0)$ & $7(13.0)$ & 54 & \\
\hline Indian & 0 & $11(100)$ & 0 & 11 & \\
\hline \multicolumn{6}{|l|}{ Total } \\
\hline$n(\%)$ & $1(0.3)$ & $266(88.4)$ & 34 (11.3) & 301 & \\
\hline $95 \% \mathrm{Cl}$ & $0.00-1.84$ & $84.20-91.77$ & $7.95-15.43$ & & \\
\hline
\end{tabular}

while most cases had three canals (58.3\%) and followed by four and two canals [Table 4]. The number of canals was not associated with ethnic group $(P>0.05)$. However, the males had significantly fewer number of canals than females $(P=0.02)$.

The distribution of canals by the number of roots is presented in Table 5. The MFPM with a single root was found to have only one mesial canal. For two-rooted MFPM, the most prevalent occurrence was two canals at the mesial and one canal at the distal roots (59\%); followed by single canals in 


\begin{tabular}{|c|c|c|c|c|c|c|c|}
\hline & One & Two & Three & Four & Five & Total & $P^{*}$ \\
\hline \multicolumn{8}{|l|}{ Sex } \\
\hline Male & $1(0.8)$ & $27(20.5)$ & $85(64.4)$ & $19(14.4)$ & 0 & 132 & 0.015 \\
\hline Female & 0 & $30(17.8)$ & $90(53.3)$ & $46(27.2)$ & $3(1.8)$ & 169 & \\
\hline \multicolumn{8}{|l|}{ Ethnic } \\
\hline Malay & $1(0.4)$ & 46 (19.5) & $136(57.6)$ & $50(21.2)$ & $3(1.3)$ & 237 & 0.7 \\
\hline Chinese & 0 & $10(18.5)$ & $34(63.0)$ & $10(18.5)$ & 0 & 54 & \\
\hline Indian & 0 & $1(9.1)$ & $5(45.5)$ & $5(45.5)$ & 0 & 11 & \\
\hline \multicolumn{8}{|l|}{ Total } \\
\hline$n(\%)$ & $1(0.3)$ & 57 (18.9) & $175(58.1)$ & 65 (21.6) & $3(1.0)$ & 301 & \\
\hline $95 \% \mathrm{Cl}$ & $0.00-1.84$ & $14.67-23.83$ & 52.34-63.77 & $17.08-26.68$ & $0.21-2.88$ & & \\
\hline
\end{tabular}

\begin{tabular}{|c|c|c|c|c|c|}
\hline $\begin{array}{l}\text { Number } \\
\text { of roots }\end{array}$ & $\begin{array}{c}\text { Mesial } \\
\text { root }\end{array}$ & $\begin{array}{c}\text { Distal } \\
\text { root }\end{array}$ & $n$ & Prevalence & $95 \% \mathrm{Cl}$ \\
\hline & - & & & & \\
\hline $1(n=1)$ & 1 & 0 & 1 & 0.3 & $0-1.83$ \\
\hline \multirow[t]{8}{*}{$2(n=266)$} & 1 & 0 & 1 & 0.3 & $0-1.83$ \\
\hline & 1 & 1 & 56 & 21.1 & $16.38-26.55$ \\
\hline & 2 & 2 & 47 & 17.7 & $13.33-22.88$ \\
\hline & 2 & 1 & 157 & 59.2 & $53.06-65.22$ \\
\hline & 3 & 1 & 1 & 0.4 & $0.00-2.08$ \\
\hline & 3 & 2 & 1 & 0.4 & $0.00-2.08$ \\
\hline & 1 & 2 & 1 & 0.4 & $0.00-2.08$ \\
\hline & 2 & 3 & 2 & 0.8 & $0.00-2.70$ \\
\hline \multirow[t]{2}{*}{$3(n=34)$} & 1 & 2 & 17 & 50.0 & $32.43-67.57$ \\
\hline & 2 & 2 & 17 & 50.0 & $32.43-67.57$ \\
\hline
\end{tabular}

each mesial and distal (21\%) and double canals per $\operatorname{root}(18 \%)$.

Three roots MFPM have either single or double canals in the mesial root and double canals in the distal root.

\section{DISCUSSION}

Root canal morphology is claimed to vary between ethnic and because of that it is important for the clinician to be aware about the variation before commencing root canal treatment. ${ }^{[20]}$ The analysis found that there the occurrence of the number of roots is independent of the sides of the jaw. It also found that the probability of finding unequal number of root between the right and left MFPM was small (4\%, 95\% CI: $0.0,9.33)$ with the majority of cases having two roots on both sides $(87 \%)$. If the right MFPM was found to have two roots, there is remote probability to find the three roots on the left side and; if it has three roots, the left side will be has $75 \%$ greater odds of having 3 roots. This is especially important in multiracial society such as Malaysia, which might pose a great challenge to dentist successfully perform root canal treatment. Untill now, there is lacking literature on root canal morphology of MFPM in Malaysian population. ${ }^{[21,22]}$ This study described the variations of MFPM of the east coast population of Malaysia. Malaysian population is a mixed between Malay, Chinese, and Indian as their three major ethnic group with other ethnic groups in smaller proportion. Previous study had suggested that the number of roots in MFPM varies between ethnic, which is contradicting to the finding in this study. In Asian population, the incidence of three rooted MFPM was higher especially in Chinese. ${ }^{[20,23-25]}$ Contrary to this, Chinese in the present study was having greater incidence of two rooted rather than three rooted in their MFPM. However, the former two ethnics were descendent of mongoloid trait ${ }^{[26,27]}$ and may be the reason for the observed result. The Indians participants in the present study were found to have two-rooted MFPM which contradicting from a previous study which found three-rooted MFPM in Indian population. ${ }^{[15]}$ This result need to be interpreted carefully as the sample size of that ethnic in the present study is small and may not fully represent the population. In addition, the result in this study might be an underinterpretation of Indian patient as according to Malaysian Constitution, any Indian-Muslims is registered as Malay in their identity card. ${ }^{[28,29]}$

The MFPM usually have two roots located on the mesial and distal, but in mongoloids population, the presence of distolingual root is considered to be a normal morphology variant and can be identified as an Asian trait. ${ }^{[8,21,23]}$ Three-rooted mandibular first molars have been reported to occur more frequently in the Mongoloid than Caucasoid race. ${ }^{[19]}$ In the current 


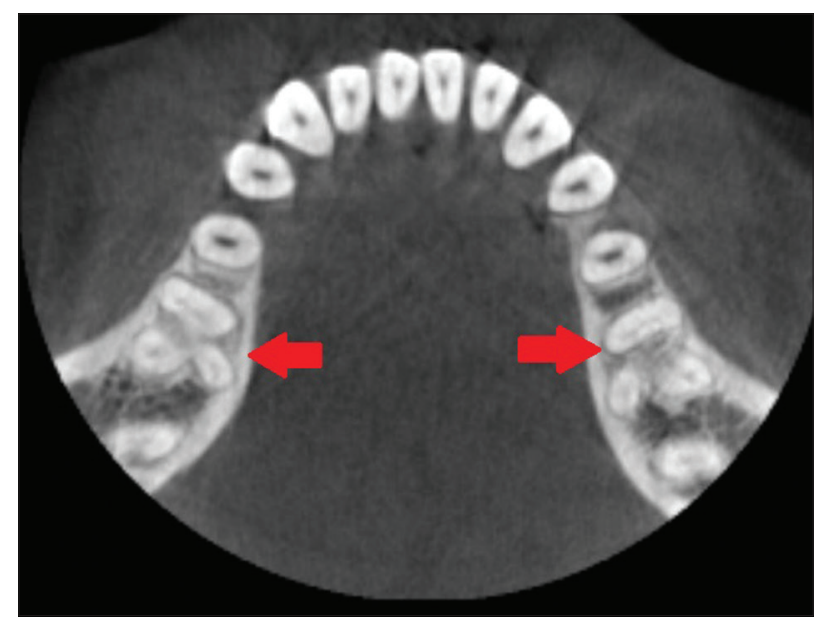

Figure 1: Mandibular first permanent molar with three roots and four canals (arrow)

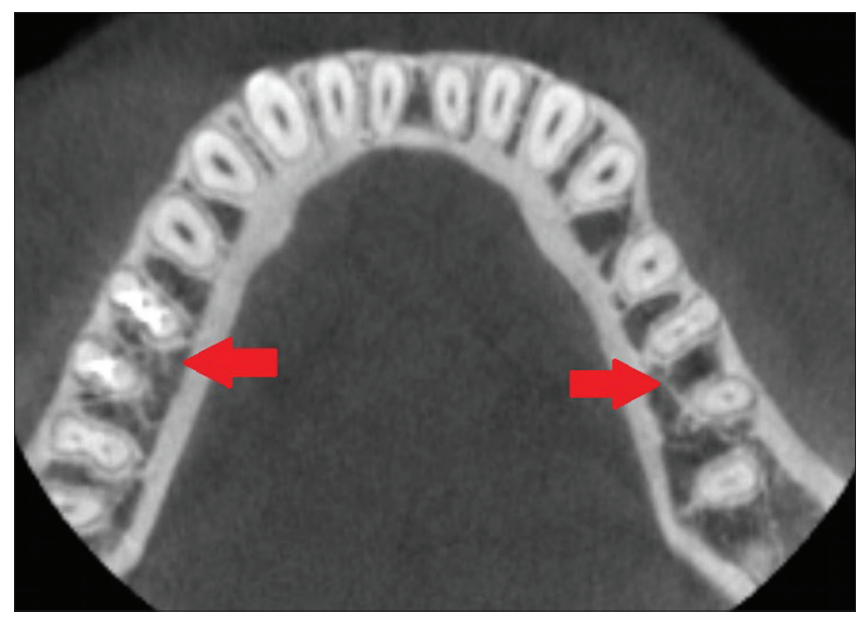

Figure 2: Tooth 36 with two roots and five canals (left arrow) and tooth 46 with two roots and three canals (right arrow)

study, an extra distolingual root was observed in $11.9 \%$ of the cases. This prevalence is lower than that found in Western China population ${ }^{[16]}(25.8 \%)$ and Taiwanese population $^{[5]}(25.3 \%)$. However, the incidence of three-rooted MFPM is higher than previous studies of Caucasians (4.3\%), ${ }^{[23]}$ Sudanese, and Senegalese (3.0\%) patients. ${ }^{[3,31]}$ It is not clear whether this variation is due to sampling variation related to location and diversity of ethnic as result of migration and mixed genetic. For example, regional differences were observed in the prevalence of three-rooted MFPM of Taiwanese, whom the prevalence was greater than other oriental populations ${ }^{[11,25]}$ and mentioned as a special characteristic of their dentition. ${ }^{[32]}$ Although the number of cases with three roots MFPM is small in the present study sample, a special attention should be given to such cases as it increases the challenge to carry out root canal cleaning and shaping of this additional root also known as radix entamolaris.
Earlier studies reported that distolingual root was more prevalent in the males. ${ }^{[0,33]}$ However, the findings from the present study was similar to Taiwanese population where no difference was found between the genders. ${ }^{[5,11]}$ Topologic predilection for the presence of extra distolingual root in the MFPMs is also a controversial issue. Some studies reported that three-rooted MFPMs was predominant on the right side, ${ }^{[11,33]}$ while others found left side predominance. ${ }^{[21,34]}$ However, there was no significant different of topologic predilection found in our study. The diversity in each outcome may be due to different methods of case selection and different sample sizes. Further investigation need to be carried out with larger sample to clarify the issue.

The prevalence of four canals in this study was lower $(22.22 \%)$ compared to Sudanese population $(59 \%) \cdot{ }^{[3]}$ However, the occurrence of two canals in our study $(23.3 \%)$ was higher than Kuwaiti $(6.1 \%),{ }^{[17]}$ Western China population (1.4\%), ${ }^{[16]}$ Indian $(6.45 \%),{ }^{[15]}$ and Taiwan $(3.4 \%)$ populations. ${ }^{[5]}$ One interesting observation in this study is that having four and five canals was significantly more prevalent in the females than males [Figures 1 and 2].

Technological advancement influences the method to investigate root canal morphology. Among the premier methods, roots were decalcified and dissected horizontally and the canals were identified from the transparent specimens under stereomicroscope at 20 times magnification. ${ }^{[35]}$ Then, the use of ink was introduced to help identify the canals. Indian ink was injected into the root canal system before the tooth was decalcified and dehydrated with alcohol to render the extracted tooth specimen transparent. ${ }^{[36]}$ Another method is by evaluating periapical radiograph, but this method resulted in very limited interpretation of 3D tooth structure ${ }^{[12]} \mathrm{CBCT}$ imaging was claimed to have a similar accuracy to the modified canal staining and tooth clearing technique. ${ }^{[19]}$ The main advantage is that it allows for $3 \mathrm{D}$ reconstruction and visualization of the external and internal anatomy of teeth which makes it more accurate than conventional radiographs. ${ }^{[37]}$

This study has the advantage of using the CBCT to examine the root and canal morphology which allows the investigation to be done in shorter time and lower cost as the sample were obtained from radiology archive. Given that the radiology assessment was carried out by a trained person, the result has a similar accuracy to the conventional slide specimen. 
However, the sample included is limited to the East Coast of Malaysian population and may not represent the Indian population very well.

\section{CONCLUSIONS}

Within the limitations of this study, the majority of the population living in the East Coast region of Malaysia have two roots and three root canals in their MFPMs. But there are cases of MPFM with four and five canals and they are significantly more prevalent in the females. CBCT is a valuable tool for identifying an extra distolingual root in mandibular first molars.

\section{Acknowledgments}

We thank the Management of the Hospital Universiti Sains Malaysia ( USM), Kubang Kerian, Kelantan for granting the permission to the investigators to use patients' medical record; space and assets belong to the hospital during the process of conducting the research. Special thanks to Mr Firdaus Daud, License Radiologist, School of Dental Sciences, USM.

\section{Financial support and sponsorship}

Nil.

\section{Conflicts of interest}

There are no conflicts of interest.

\section{REFERENCES}

1. Witherspoon DE, Small JC, Regan JD. Missed canal systems are the most likely basis for endodontic retreatment of molars. Tex Dent J 2013;130:127-39.

2. Zadik Y, Sandler V, Bechor R, Salehrabi R. Analysis of factors related to extraction of endodontically treated teeth. Oral Surg Oral Med Oral Pathol Oral Radiol Endod 2008;106:e31-5.

3. Ahmed HA, Abu-bakr NH, Yahia NA, Ibrahim YE. Root and canal morphology of permanent mandibular molars in a Sudanese population. Int Endod J 2007;40:766-71.

4. Chandra SS, Chandra S, Shankar P, Indira R. Prevalence of radix entomolaris in mandibular permanent first molars: A study in a South Indian population. Oral Surg Oral Med Oral Pathol Oral Radiol Endod 2011;112:e77-82.

5. Huang CC, Chang YC, Chuang MC, Lai TM, Lai JY, Lee BS, et al. Evaluation of root and canal systems of mandibular first molars in Taiwanese individuals using cone-beam computed tomography. J Formos Med Assoc 2010;109:303-8.

6. Park JB, Kim N, Park S, Kim Y, Ko Y. Evaluation of root anatomy of permanent mandibular premolars and molars in a Korean population with cone-beam computed tomography. Eur J Dent 2013;7:94-101.

7. Park JB, Kim N, Park S, Ko Y. Evaluation of number of roots and root anatomy of permanent mandibular third molars in a Korean population, using cone-beam computed tomography. Eur J Dent 2013;7:296-301.

8. Schäfer E, Breuer D, Janzen S. The prevalence of three-rooted mandibular permanent first molars in a German population. J Endod 2009;35:202-5.

9. Schumacher C. Endodontic treatment of a mandibular first molar with radix entomolaris: A case report. Endod Pract Today 2008;2:301-4.

10. Shemesh A, Levin A, Katzenell V, Ben Itzhak J, Levinson O, Zini A, et al. Prevalence of 3- and 4-rooted first and second mandibular molars in the Israeli population. J Endod 2015;41:338-42.

11. Tu MG, Tsai CC, Jou MJ, Chen WL, Chang YF, Chen SY, et al. Prevalence of three-rooted mandibular first molars among Taiwanese individuals. J Endod 2007;33:1163-6.

12. Yang Y, Zhang LD, Ge JP, Zhu YQ. Prevalence of 3-rooted first permanent molars among a Shanghai Chinese population. Oral Surg Oral Med Oral Pathol Oral Radiol Endod 2010;110:e98-101.

13. Touré B, Faye B, Kane AW, Lo CM, Niang B, Boucher Y, et al. Analysis of reasons for extraction of endodontically treated teeth: A prospective study. J Endod 2011;37:1512-5.

14. Nur BG, Ok E, Altunsoy M, Aglarci OS, Colak M, Gungor E, et al. Evaluation of the root and canal morphology of mandibular permanent molars in a South-Eastern Turkish population using cone-beam computed tomography. Eur J Dent 2014;8:154-9.

15. Reuben J, Velmurugan N, Kandaswamy D. The evaluation of root canal morphology of the mandibular first molar in an Indian population using spiral computed tomography scan: An in vitro study. J Endod 2008;34:212-5.

16. Wang $\mathrm{Y}$, Zheng $\mathrm{QH}$, Zhou XD, Tang $\mathrm{L}$, Wang $\mathrm{Q}$, Zheng GN, et al. Evaluation of the root and canal morphology of mandibular first permanent molars in a Western Chinese population by cone-beam computed tomography. J Endod 2010;36:1786-9.

17. Zaatar EI, al Anizi SA, al Duwairi Y. A study of the dental pulp cavity of mandibular first permanent molars in the Kuwaiti population. J Endod 1998;24:125-7.

18. Curzon ME. Miscegenation and the prevalence of three-rooted mandibular first molars in the Baffin Eskimo. Community Dent Oral Epidemiol 1974;2:130-1.

19. Neelakantan P, Subbarao C, Subbarao CV. Comparative evaluation of modified canal staining and clearing technique, cone-beam computed tomography, peripheral quantitative computed tomography, spiral computed tomography, and plain and contrast medium-enhanced digital radiography in studying root canal morphology. J Endod 2010;36:1547-51.

20. Walker RT. Root form and canal anatomy of mandibular first molars in a Southern Chinese population. Endod Dent Traumatol 1988;4:19-22.

21. Loh HS. Incidence and features of three-rooted permanent mandibular molars. Aust Dent J 1990;35:434-7.

22. Tratman E. Three-rooted lower molars in man and their racial distribution. Br Dent J 1938;64:74.

23. de Souza-Freitas JA, Lopes ES, Casati-Alvares L. Anatomic variations of lower first permanent molar roots in two ethnic groups. Oral Surg Oral Med Oral Pathol 1971;31:274-8.

24. Reichart PA, Metah D. Three-rooted permanent mandibular first molars in the Thai. Community Dent Oral Epidemiol 1981;9:191-2.

25. Tu MG, Huang HL, Hsue SS, Hsu JT, Chen SY, Jou MJ, et al. Detection of permanent three-rooted mandibular first molars by cone-beam computed tomography imaging in Taiwanese individuals. J Endod 2009;35:503-7.

26. Green RM. The position of the mental foramen: A comparison between the Southern (Hong Kong) Chinese and other ethnic and racial groups. Oral Surg Oral Med Oral Pathol 1987;63:287-90.

27. Manabe Y, Ito R, Kitagawa Y, Oyamada J, Rokutanda A, Nagamoto S, et al. Non-metric tooth crown traits of the Thai, Aka and Yao tribes of Northern Thailand. Arch Oral Biol 1997;42:283-91.

28. Chuah OA, Shukri AS, Yeoh MS. Indian muslims in Malaysia: A sociological analysis of a minority ethnic group. J Muslim Minor Aff 2011;31:217-30.

29. Stark J. Indian muslims in Malaysia: Images of shifting identities in the multi-ethnic state. J Muslim Minor Aff 2006;26:383-98.

30. Turner CG $2^{\text {nd }}$. Three-rooted mandibular first permanent molars and the question of American Indian origins. Am J Phys Anthropol 1971;34:229-41

31. Sperber GH, Moreau JL. Study of the number of roots and canals in senegalese first permanent mandibular molars. Int Endod J 1998;31:117-22

32. Miloglu O, Arslan H, Barutcigil C, Cantekin K. Evaluating root and canal configuration of mandibular first molars with cone beam computed tomography in a Turkish population. J Dent Sci 2013;8:80-6.

33. Song JS, Kim SO, Choi BJ, Choi HJ, Son HK, Lee JH, et al. Incidence and relationship of an additional root in the mandibular first permanent molar and primary molars. Oral Surg Oral Med Oral Pathol Oral Radiol Endod 2009;107:e56-60. 
Deng, et al:: Root canal morphology of first permanent molar

34. Gulabivala K, Opasanon A, Ng YL, Alavi A. Root and canal morphology of Thai mandibular molars. Int Endod J 2002;35:56-62.

35. Manning SA. Root canal anatomy of mandibular second molars. Part I. Int Endod J 1990;23:34-9.
36. Gulabivala K, Aung TH, Alavi A, Ng YL. Root and canal morphology of burmese mandibular molars. Int Endod J 2001;34:359-70.

37. Nair MK, Nair UP. Digital and advanced imaging in endodontics: A review. J Endod 2007;33:1-6. 